\title{
SINGLE SEX ALATE PRODUCTION BY COLONIES OF PHEIDOLE DESERTORUM AND PHEIDOLE XEROPHILA TUCSONICA (HYMENOPTERA: FORMICIDAE)*
}

\author{
By Ken R. Helms and Steven W. Rissing \\ Department of Zoology, \\ Arizona State University, Tempe, Arizona 85287-1501
}

Specialization in production of the sexes is widespread in ants; individual colonies often produce a sex-biased ratio of reproductive offspring (Kannowski 1963, Pamilo and Rosengren 1983, Nonacs $1986 \mathrm{a}, \mathrm{b})$. Reasons for specialization are unclear, although there is much speculation (Pamilo and Rosengren 1983, Nonacs 1986b, Frank 1987, Boomsma and Grafen 1990). While some colonies produce unisexual or extremely sex-biased broods, other colonies within the same populations will produce both males and gynes in nearly equal proportions (Pamilo and Rosengren 1983, Nonacs 1986b). A more extreme form of specialization in sexual production occurs within the genus Pheidole; all colonies within a population may exhibit specialization to the point of producing only unisexual, or nearly unisexual reproductive broods. We have investigated this phenomenon in two common desert Pheidole species.

\section{Materials AND Methods}

Partial excavations and censuses were made of $P$. xerophila tucsonica nests at South Mountain Park, Phoenix, Arizona in August 1987. Collections and censuses of $P$. desertorum colonies were made at $2.5 \mathrm{mi}$. N.W. of Rodeo, New Mexico in June and July of 1988 and 1989. Pheidole desertorum evacuate the nest in response to attack by Neivamyrmex army ants (Mirenda et al. 1980); this behavior was exploited to trap complete colonies which were censused later. Traps consist of an open (top and bottom) plastic bowl cemented into an uncovered, fluon-lined plastic box. The bottom edge of the bowl extends below the bottom of the box and is pushed into the soil around $P$. desertorum nest entrances. Army ants are introduced ad libitum into the bowl; $P$. desertorum flee from the

*Manuscript received by the editor May 23, 1990. 
nest, out of the bowl, and fall into the box. The sex produced by $P$. desertorum colonies left intact in the field was assessed by placing a concave stone over the nest entrance and pouring water over and around the stone. Alates moved under the stone into the humid chamber; the stone was lifted and number and sex of alates were recorded.

\section{RESUlTS}

In P. xerophila tucsonia, alate production by colonies appeared strictly unisexual; only males were found in 13 colonies (mean number $=30.62, \mathrm{SD}=33.62)$ and only gynes were found in 6 colonies (mean number $=16.00, \mathrm{SD}=21.82$ ). In $P$. desertorum colonies assessed and left intact in the field, only males were found in 46 colonies (mean number $=27.30, \mathrm{SD}=40.30$ ) and only gynes were found in 64 colonies (mean number $=15.61, \mathrm{SD}=17.56$ ). Both sexes were found in only 5 colonies (mean number of males $=$ $18.00, \mathrm{SD}=32.08$; mean number of gynes $=2.40, \mathrm{SD}=1.34$ ). Complete colony census data (Table 1) suggest mixed-sex reproductive broods are produced by male specialist colonies which produce a small number of gynes.

Table 1. Census of males and gynes present in complete $P$. desertorum colonies.

\begin{tabular}{lrrrrrrrr}
\hline & \multicolumn{10}{c}{ Colony Designation } \\
\cline { 2 - 9 } & $A 1$ & $A 4$ & $A 8$ & $X 1$ & $A 9$ & $X 3$ & $A 6$ & $A 5$ \\
\hline \# Males & 356 & 535 & 711 & 1,076 & 0 & 0 & 0 & 0 \\
\# Gynes & 1 & 0 & 9 & 1 & 3 & 198 & 246 & 434 \\
\hline
\end{tabular}

\section{Discussion}

Specialization in production of the sexes is more extreme in $P$. desertorum and $P$. xerophila tucsonica than has been reported to occur in other ants. Droual (1982) observed 40 reproductive $P$. desertorum colonies which evacuated the nest in response to introduction of Neivamyrmex nigrescens army ants. Twenty-two colonies produced only gynes; the remaining 18 produced only males or a sex ratio "strongly" male-biased. These observations are consistent with data presented here. Pheidole desertorum colonies produce either all gynes, all males, or nearly all males. Only unisexual reproductive broods were observed for $P$. xerophila tucsonica. 
Proposed circumstances under which natural selection may result in specialization by ant colonies include avoidance of inbreeding (Marikovsky 1961), queen-worker conflict over investment ratio (Pamilo 1982, Boomsma and Grafen 1990), efficient use of resources (Nonacs 1986b), and intrasexual competition among relatives (Frank 1987). Selection against specialization should be strong in small populations (Taylor and Sauer 1980), and selection to maintain specialization may be weak when population investment ratio is at, or near equilibrium (Frank 1987). Differing magnitude of selection pressures both favoring and opposing specialization might result in differing degrees of specialization, including extreme specialization found within Pheidole.

\section{SUMMARY}

Pheidole desertorum and P. xerophila tucsonica appear unusual among ants in that colonies produce only unisexual or extremely sex-biased reproductive broods. Specialization in production of the sexes may be more extreme within Pheidole than other ants due to difference between ant taxa in magnitude of selection pressures both favoring and opposing specialization.

\section{ACKNOWLEDGEMENTS}

We thank the staff of the Southwestern Research Station of the American Museum of Natural History for their hospitality and N. Hall for permission to work on his land near Rodeo. E. Deely and S. Lyons provided appreciated assistance in the field. D. Wheeler first brought our attention to specialization within Pheidole and made helpful comments on a previous version of the manuscript. Support was provided by the A.S.U. Dept. of Zoology Graduate Research Fund and the Theodore Roosevelt Memorial Fund.

\section{Literature Cited}

Boomsma, J. J. AND A. Grafen.

1990. Intraspecific variation in ant sex ratios and the Trivers-Hare hypothesis. Evolution. 44: 1026-1034.

Droual, R.

1982. Sex ratios in the ant Pheidole desertorum. Am. Zool. 22: 971. 
Frank, S. A.

1987. Variable sex ratio among colonies of ants. Behav. Ecol. Sociobiol. 20: 195-201.

KanNowsKi, P. B.

1963. The flight activities of formicine ants. Symp. Gen. Biol. Ital. 12: 74-102. MARIKOVSKY, P. I.

1961. Material on sexual biology of the ant Formica rufa L. Ins. Soc. 8: 23-30. Mirenda, J. T., Eakins, D. G., Gravelle, K. and H. Topoff.

1980. Predatory behavior and prey selection by army ants in a desert-grassland habitat. Behav. Ecol. Sociobiol. 7: 119-127.

Nonacs, $P$.

1986a. Sex-ratio determination within colonies of ants. Evolution 40: 199-204.

1986b. Ant reproductive strategies and sex allocation theory. Q. Rev. Biol. 61: $1-21$.

Pamilo, P.

1982. Genetic evolution of sex ratios in eusocial Hymenoptera: allele frequency simulations. Am. Nat. 119: 638-656.

Pamilo, P. and R. Rosengren.

1983. Sex ratio strategies in Formica ants. Oikos 40: 24-35.

TAYLOR, P. D. AND A. SAUER.

1980. The selective advantage of sex-ratio homeostasis. Am. Nat. 116: 305-310. 

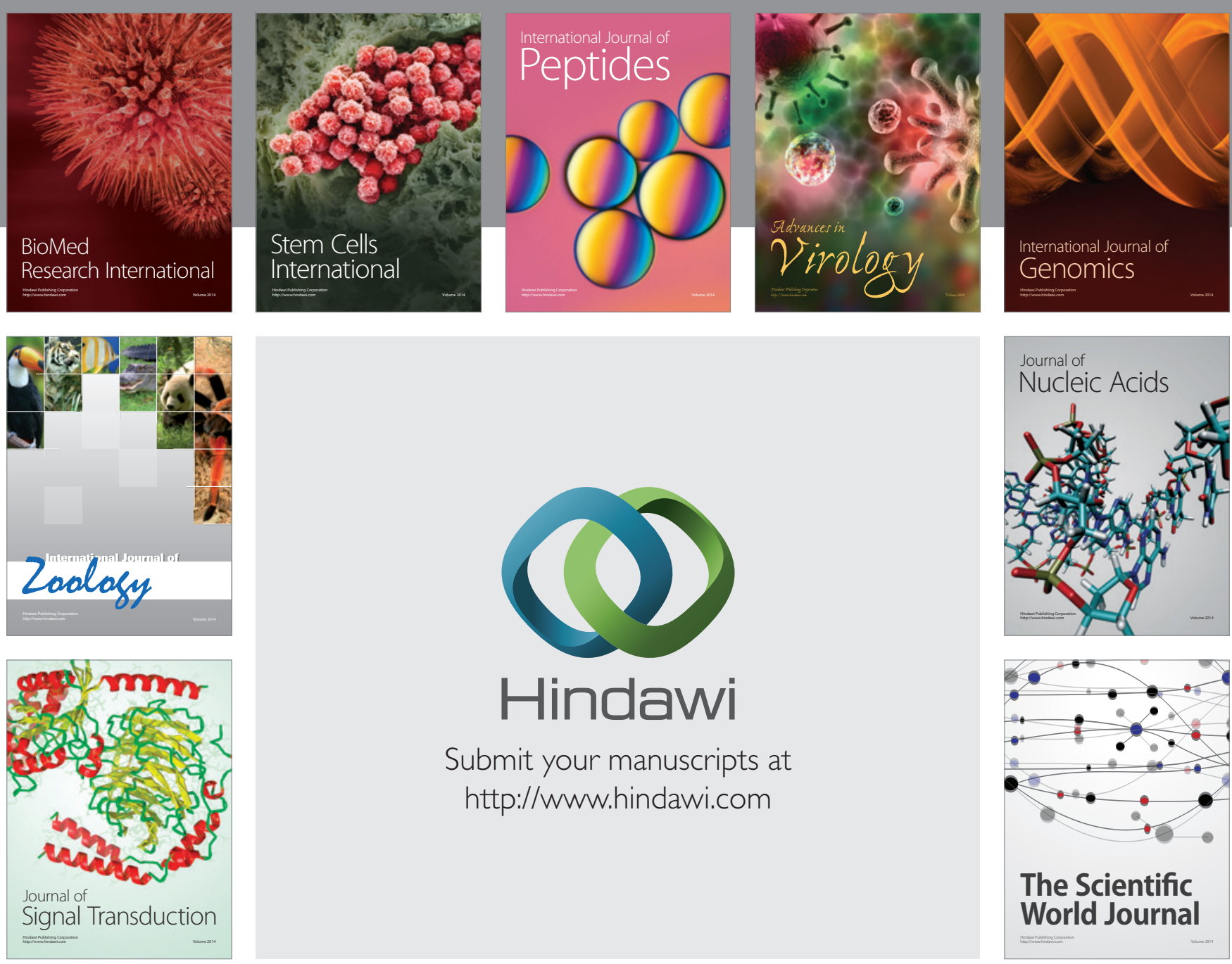

Submit your manuscripts at

http://www.hindawi.com
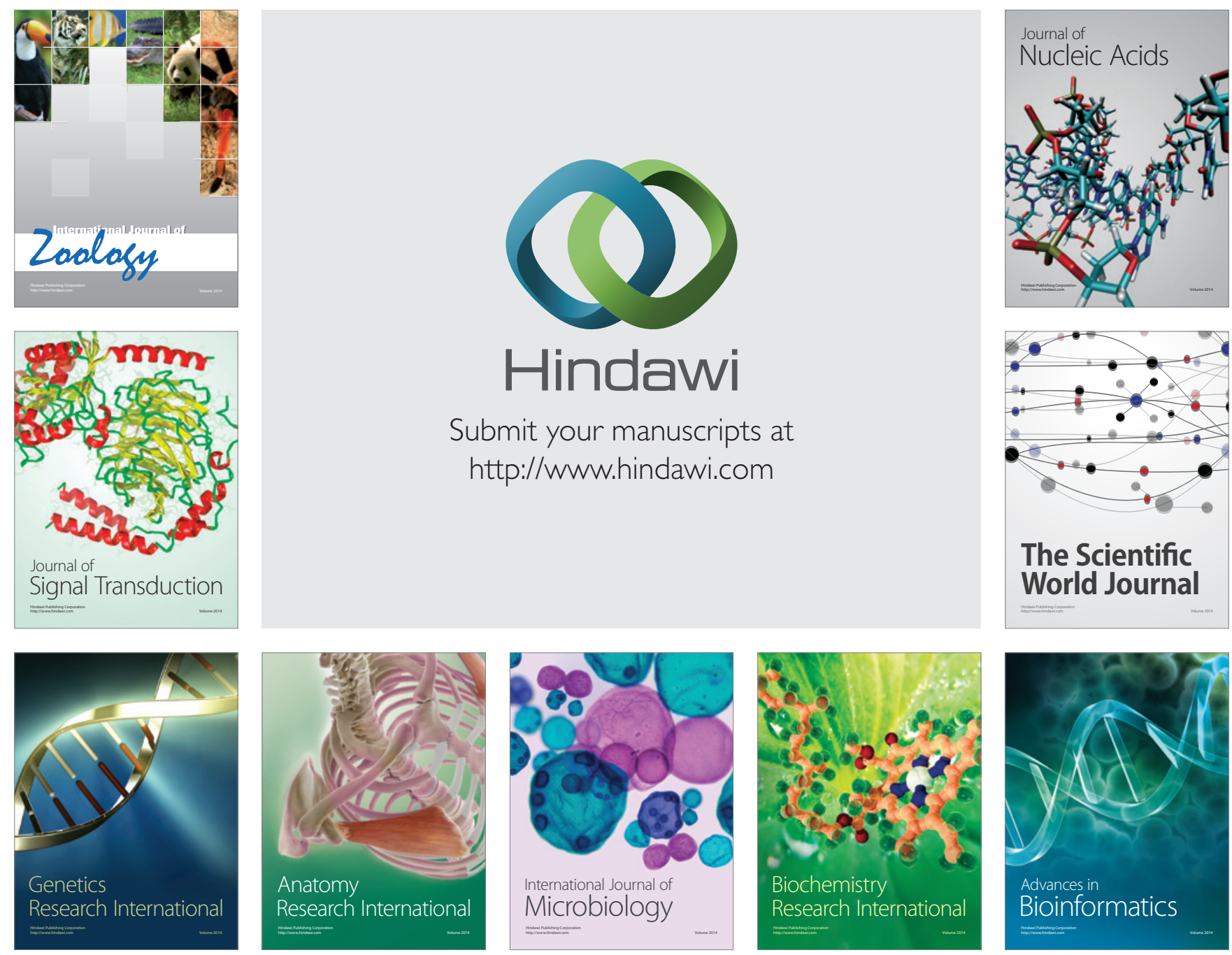

The Scientific World Journal
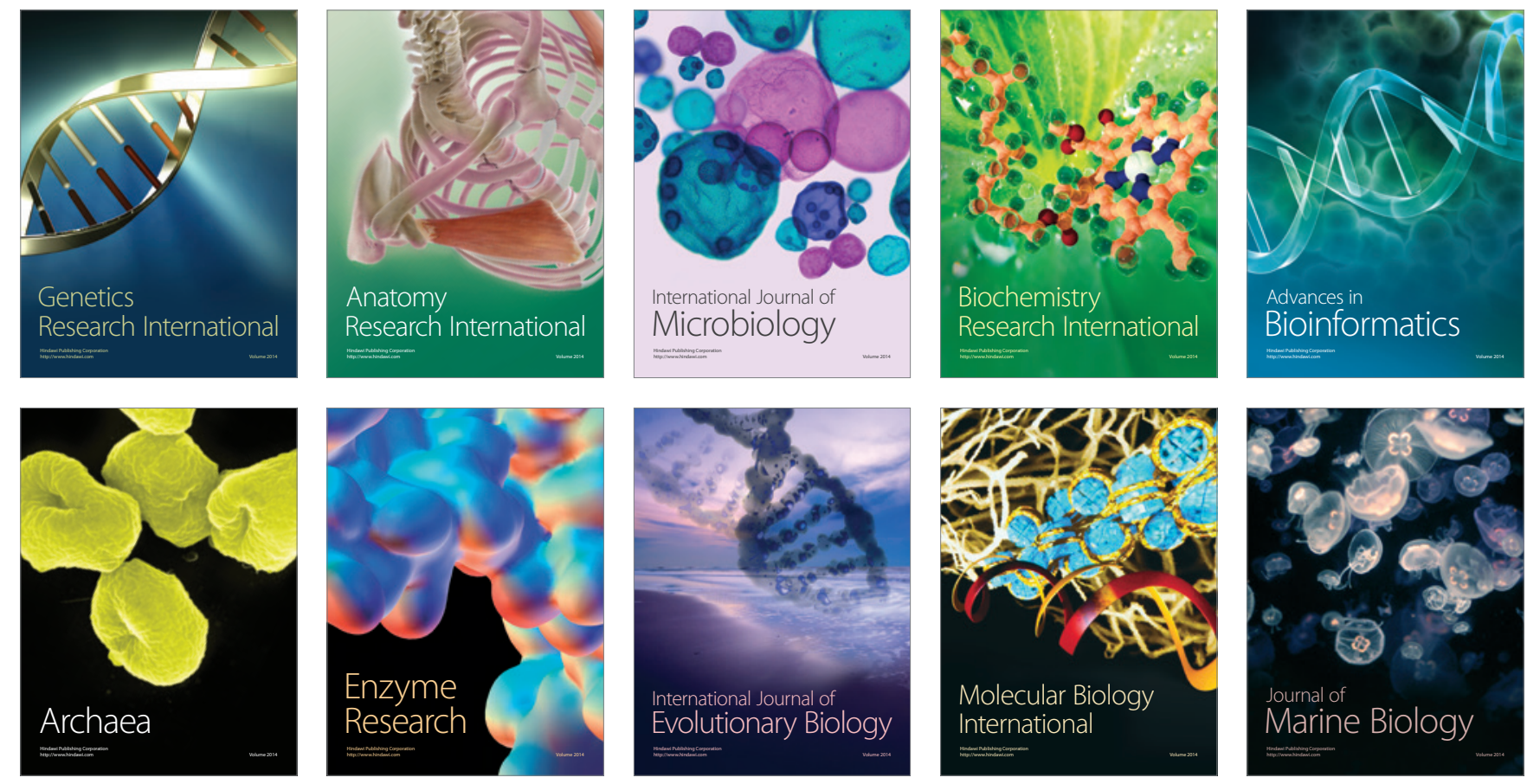